\title{
Interacting effects of aromatic plants and female age on nest-dwelling ectoparasites and blood-sucking flies in avian nests
}

\author{
G. Tomás*, S. Merino, J. Martínez-de la Puente ${ }^{1}$, J. Moreno, J. Morales, E. Lobato ${ }^{2}$, \\ J. Rivero-de Aguilar, S. del Cerro \\ Departamento de Ecología Evolutiva, Museo Nacional de Ciencias Naturales (CSIC), J. Gutiérrez Abascal 2, E-28006 Madrid, Spain
}

Keywords:

Antiparasite defence

Biting flies

Ceratopogonidae

Culicoides

Greenery

Simuliidae

\begin{abstract}
a b s $\mathbf{t} \mathbf{r}$ a $\mathrm{c}$ t
Some avian species incorporate aromatic plants to their nests. The "nest protection hypothesis", which posits that volatile secondary compounds contained in these plants may have antiparasite properties, has not received full support. All previous tests of this hypothesis have only considered effects on nestdwelling ectoparasites, but not on blood-sucking flies. The "drug hypothesis" posits that aromatic plants may stimulate nestling immune system, development, or condition. We tested these hypotheses experimentally in wild blue tits Cyanistes caeruleus, a species that adds aromatic plants to their nests. We supplemented aromatic plants to half of a sample of nests, while adding grass to the other half of nests. We quantified abundance of two groups of blood-sucking flies (blackflies and biting midges) at two different stages of the reproductive period, and abundance of three nest-dwelling ectoparasites (fleas, mites, and blowflies). Experimental supplementation of aromatic plants reduced abundance of fleas only in nests of yearling females and not in nests of older females. Blackflies and biting midges were both more numerous in nests of yearling females than in nests of older females. Mass of aromatic plants added by females was negatively related with abundance of fleas in control nests but not in experimental nests supplied with aromatic plants. Mass of plants added by females was also positively related with abundance of blackflies during the nestling stage. Finally, aromatic plants did not affect nestling growth or immune responses. We conclude that several factors such as female experience and their ability to add plants to the nest interact to explain effects of aromatic plants on different parasites.
\end{abstract}

\section{Introduction}

Some avian species, from raptors to passerines, incorporate pieces of fresh, aromatic plants in their nests during different phases of the breeding cycle (e.g. Clark and Mason, 1985; Wimberger, 1984), a behaviour that has long puzzled biologists (e.g. Bucher, 1988; Rheinwald, 1972; Taverner, 1933) and is still the focus of intense debate (e.g. Mennerat et al., 2009a; Veiga et al., 2006). Among the many hypotheses to explain the functional significance of this behaviour, three non-mutually exclusive hypotheses have captured the most attention by researchers. The courtship hypothesis posits that birds bring aromatic plants to the nest as a

\footnotetext{
* Corresponding author at: Departamento de Ecología Funcional y Evolutiva, Estación Experimental de Zonas Áridas (CSIC), Carretera de Sacramento, s/n. E-04120 La Cañada de San Urbano-Almería, Spain. Tel.: +34950281045; fax: +34950277100. E-mail address: gtomas@eeza.csic.es (G. Tomás).

1 Present address: Departamento de Ecología de Humedales, Estación Biológica de Doñana (EBD-CSIC), Americo Vespucio s/n, E-41092 Sevilla, Spain.

2 Present address: Centre d'Ecologie Fonctionelle et Evolutive, CNRS, 1919 Route de Mende, Montpellier, France.
}

sexual display (e.g. Brouwer and Komdeur, 2004; Fauth et al., 1991; Veiga et al., 2006). The nest protection hypothesis posits that birds bring aromatic plants to the nest because of the volatile secondary compounds contained in plants, which may have antiparasite properties (e.g. Clark, 1991; Shutler and Campbell, 2007; Wimberger, 1984). The observation that experimental supplementation of aromatic plants did not affect nest-dwelling ectoparasites but improved nestling mass and haematocrit prompted the drug hypothesis, which posits that aromatic plants may directly stimulate nestling immune system, development, or condition (Gwinner et al., 2000).

Overall, functional significance of addition of aromatic plants to nests is not fully understood, and it may well be that it serves different functions depending upon species. In European starlings (Sturnus vulgaris) and spotless starlings (Sturnus unicolor), green plants are brought to nests by males mainly during courtship (Clark and Mason, 1985; Gwinner, 1997; Veiga et al., 2006). Clark and Mason (1988) suggested an effect of addition of aromatic plants in reducing ectoparasitic mite loads in starling nests. However, most other studies carried out afterwards on starlings have failed to find any effect of aromatic plants on nest-dwelling ectoparasites, 

including not only mites (Brouwer and Komdeur, 2004; Fauth et al., 1991; Gwinner and Berger, 2005; Gwinner et al., 2000), but also lice and fleas (Gwinner et al., 2000). To date, most evidence from studies carried out on starlings is in accordance with the courtship hypothesis (e.g. Brouwer and Komdeur, 2004; Gwinner, 1997; Polo et al., 2004; Veiga et al., 2006).

In blue tit (Cyanistes caeruleus) nests, aromatic plants are incorporated by females (Banbura et al., 1995; Cowie and Hinsley, 1988). Different plant species are selected based on individual preferences (Mennerat et al., 2009b). Females start bringing aromatic plants from the time nest cup is finished, and may keep adding aromatic plants up to first days after hatching (authors, pers. obs., see also Banbura et al., 1995; Cowie and Hinsley, 1988) and, in some populations, even until nestlings are ready to fledge (Lambrechts and Dos Santos, 2000; Mennerat et al., 2009a). In experimental studies, Mennerat et al. (2008) failed to find any effect of aromatic plants on blowfly parasitism, while improved nestling growth was found in certain years or in experimentally enlarged broods after removing nest-dwelling ectoparasites (Mennerat et al., 2009a). Thus, evidence up to date on blue tits appears to support the drug hypothesis, although a mechanism underlying such benefits was recently suggested. Mennerat et al. (2009c) showed that experimental supplementation of aromatic plants reduces abundance and diversity of the bacterial community living on skin and feathers of nestlings.

The nest protection hypothesis has also been tested in different avian species. For example, in Bonelli's eagles (Aquila fasciatus), adults carry large amounts of green material (mainly from pines) to their nests, and its abundance correlates negatively with abundance of blowfly larvae in nests (Ontiveros et al., 2008). By contrast, studies on a species that does not incorporate aromatic plants to the nest, the tree swallow Tachycineta bicolor, found either an increase (Dawson, 2004) or a reduction (Shutler and Campbell, 2007) in abundance of fleas, after experimentally adding aromatic plants to their nests. Finally, Dawson (2004) did not find any effect of addition of aromatic plants on blowfly abundances in tree swallow nests.

Incongruent results obtained for the nest protection hypothesis could be due to unobserved parasites, and blood-sucking flies have been repeatedly suggested as a candidate target for this behaviour (Dawson, 2004; Lafuma et al., 2001; Mennerat et al., 2008; Wimberger, 1984). To our knowledge, the only attempt to formally test this possibility comes from a laboratory experiment with caged domestic chicks, where Lafuma et al. (2001) showed that a mixture of aromatic plants appeared to repel Culex pipiens mosquitoes from taking a blood meal. However, whether addition of aromatic plants to avian nests has a repellent effect against blood-sucking flies under natural conditions remains currently unexplored. Moreover, wild birds appear to be challenged more often by blood-sucking flies other than mosquitoes, namely biting midges and blackflies (Malmqvist et al., 2004; Martínez-de la Puente et al., 2009a; Mellor et al., 2000; Tomás et al., 2008a; Votýpka et al., 2009). Indeed, if aromatic plants reduced abundance of these blood-sucking flies, it could explain why Gwinner et al. (2000) and Mennerat et al. (2009a) found no effect on nest-dwelling ectoparasites after experimental supplementation of aromatic plants, but did find improved nestling mass gain and haematocrit. Blood-sucking flies could mediate those associations, because they can impair nestling condition (Martínez-de la Puente et al., 2010; Tomás et al., 2008b).

The aim of this study was to test two non-mutually exclusive hypotheses to explain addition of aromatic plants in avian nests: the nest protection hypothesis (Clark and Mason, 1985; Wimberger, 1984) and the drug hypothesis (Gwinner et al., 2000). According to the nest protection hypothesis, we expected that by experimentally supplementing aromatic plants in blue tit nests, abundance of parasites would be reduced. We recorded abundance of blood-sucking flies (biting midges and blackflies) during incubation and during nestling period. Aromatic plants may protect incubating females from these insects (e.g. Banbura et al., 1995; Cowie and Hinsley, 1988), though to our knowledge this hypothesis has never been tested before. We also recorded abundance of three nest-dwelling ectoparasites (mites, fleas, and blowflies) and a parasitoid of blowflies. Blowflies suck blood only as larvae, while parasitoids affect blowfly pupae (i.e. the next stage), and both complete a single generation during the nestling period. Attracting parasitoids may thus be adaptive if blue tits raise a second brood in the same (or a nearby) nest, because both insects show limited dispersal distances and can produce a second generation in second broods of hosts (Bennett and Whitworth, 1991, 1992; Whiting, 1967). Blue tits in our population do not raise second broods, but second broods have been reported in $48 \%$ of blue tit populations studied, involving up to $38 \%$ of breeding pairs (Fargallo, 2004). We expected that if addition of aromatic plants in nests functions to attract this parasitoid, nests experimentally supplemented with aromatic plants would show larger abundances of this parasitoid (see Dawson, 2004), something that has not been tested before.

According to the drug hypothesis, we expected that by experimentally supplementing aromatic plants in nests, growth and/or immune response of nestlings would be enhanced, independently of parasites loads in nests, i.e. without affecting parasite abundances.

\section{Materials and methods}

\subsection{Study species and area}

The blue tit C. caeruleus is a small (10-12-g) hole-nesting passerine that is common in mixed and deciduous forests throughout the Western Palaearctic (Cramp and Perrins, 1998) and readily accepts nestboxes to breed when provided. The study was carried out during the 2006 breeding season in a population of blue tits breeding in wooden nest-boxes in a Pyrenean oak Quercus pyrenaica deciduous forest located in Valsaín (Segovia, central Spain, $40^{\circ} 53^{t} \mathrm{~N}, 4^{\circ} 01^{t} \mathrm{~W}$, $1200 \mathrm{~m}$ a.s.l.; e.g. Fargallo and Johnston, 1997; Merino et al., 2006).

\subsection{Field and experimental protocols}

Nest-boxes were inspected every third day from the first week of April. Once a tit nest (both great tits Parus major and blue tits in our study area build similar nests; Moreno et al., 2009) was found finished (cup-shaped and covered with lining materials), it was alternately assigned to either the aromatic plants group (hereafter aromatic nests) or to the control group (hereafter control nests). Later exclusion of great tit nests, together with a few failed or deserted nests, explains unequal sample sizes between treatments. Every third day, we spread $0.5 \mathrm{~g}$ of aromatic plants (species information given below) on the nest rim in "aromatic nests", whereas we spread $0.5 \mathrm{~g}$ of grass in "control nests". This amount is within the range of natural variation in the population (authors unpublished data). Addition of grass in control nests matched the sudden appearance of new plants on the nest rim that might disturb the birds. In both groups, plant fragments of similar size to those added by blue tits were harvested from several cultured plants prior to deposition in nests. Two plant species were chosen for the aromatic group: Lavandula stoechas $(0.25 \mathrm{~g})$ and Santolina chamaecyparissus $(0.25 \mathrm{~g})$. Selection of these species was made according to previous observations of plants incorporated by blue tits in our population and a review of literature of green plant addition in other areas (Lambrechts and Dos Santos, 2000; Petit et al., 2002; Polo et al., 2004). Comparing four selected plant species that blue tits bring to their nests, L. stoechas showed the larger effect in repelling 
mosquitoes from taking a blood meal from domestic chicks in a laboratory experiment (Lafuma et al., 2001). Every third day, nests were visited and any plant fragments added by blue tits were carefully collected in bags, allowed to dry, and weighed to the nearest $0.001 \mathrm{~g}$ to obtain total dry mass of aromatic plants added by birds per nest (hereafter mass of plants) that was included in analyses. In every visit, we removed previous supplemented plants present in the nest, and we delivered $0.5 \mathrm{~g}$ of fresh plant fragments. Plant fragments can dry out after a couple of days in the nest (Lambrechts and Dos Santos, 2000), so by replacing them every third day we assume that aromatic plants should have been effective for most of the time that the experiment lasted. We supplemented plants every third day until egg hatching, which was determined through daily inspections of nests around expected hatching date (previous visits allowed us to determine laying dates $(1=1$ April) and clutch sizes). The last plant supplementation took place with newly born nestlings, either at day 0 (hatching date of the first egg), day 1 , or day 2 post-hatching, and presumably their effects lasted, accordingly, at least up to 3-5 days post-hatching. Gwinner and Berger (2005) showed that plant volatile compounds are traceable in the nestbox air environment even several weeks after plant deposition. Overall, experimental plants were supplemented to nests 10.4 times on average (range 8-13), extended during a period of 31.3 days on average (range 24-39).

\subsection{Parasite quantification}

Blood-sucking flies belonging to the families Ceratopogonidae (biting midges, Culicoides spp., Martínez-de la Puente et al., 2009b) and Simuliidae (blackflies) were sampled twice, during incubation and during nestling-rearing period (three consecutive days in each period). Flies were sampled with a plastic Petri dish covered with commercially available body gel-oil where insects become glued placed inside and close to the roof of nestboxes as described in Tomás et al. (2008a). The Petri dish was supported on a wire netting, thus preventing any contact between gel-oil and birds (see Tomás et al., 2008a). During the incubation period devices were placed in nestboxes five days before expected hatching date and removed three days later, whereas during the nestling rearing period devices were placed from day 10 until day 13 of nestling age. After removal, Petri dishes were transported in cool boxes to the laboratory and stored frozen until examination under a binocular lens for fly quantification.

Just after nestlings fledged, i.e. 20 days post-hatching (blue tits fledge at 16-22 days of age), we carefully collected the nests and any nest debris from nestboxes in individually labelled sealed plastic bags and stored them at $4{ }^{\circ} \mathrm{C}$ until we examined them for nest-dwelling ectoparasites. Within a month of collection, nests were defaunated in Berlese funnels for $24 \mathrm{~h}$, under constant temperature and illumination conditions provided by a lamp placed above nests (see Tomás et al., 2007). This approach is one of the most rigorous for counting some nest-dwelling ectoparasites such as mites (Proctor and Owens, 2000). Small nest ectoparasites (mites Dermanyssus gallinoides and fleas Ceratophyllus gallinae) were collected in vials containing $70 \%$ ethanol and counted under a binocular microscope as described in Merino and Potti (1995). Abundance of Nasonia vitripennis, a tiny pteromalid parasitoid wasp of blowflies Protocalliphora azurea was also estimated from Berlese counts. We assumed that obtained abundances of this parasitoid may be underestimates of real abundances due to the quantification method, but it is very likely that both measures are correlated. We then carefully dismantled the nests in search of blowfly pupae, larvae, or its parasitoids, as well as mites, fleas, or other ectoparasites not obtained by this method (see Merino and Potti, 1995).
2.4. Female and nestling measurements and nestling immune response estimation

Female blue tits were trapped in nestboxes twice, when they were feeding 3 and 13-days-old nestlings. Birds were aged as yearlings or older (adults hereafter) according to plumage characteristics (Svensson, 1992) and ringed with numbered aluminium rings if they were not already ringed (ringing permit by regional authorities). They were weighed with a field precision balance ( \pm 0.1 g, Pocket-240; Gram Precision, Barcelona, Spain) on both captures, and their tarsus length was measured with a digital caliper $( \pm 0.01 \mathrm{~mm})$ on their second capture. We used mass/tarsus length, as an index of female body condition. Number of nestlings was counted on both visits.

At 12 days of age, three nestlings chosen at random from each nest were subjected to the single-wing phytohaemagglutinin (PHA) assay (e.g. Merino et al., 1999; Smits et al., 1999) to estimate their cell mediated immunocompetence (see Martin et al., 2006). PHA skin test is routinely used in studies of avian immunocompetence and a detailed study by Merino et al. (1999) found no adverse effects of PHA injection on several haematological parameters including physiological stress responses, and found no effect on nestling survival. Three replicate measurements of the patagium thickness $( \pm 0.01 \mathrm{~mm})$ were obtained with a digital spessimeter (Mitutoyo 7/547, Tokyo, Japan) before injecting $0.2 \mathrm{mg}$ of PHA in $0.04 \mathrm{~mL}$ of saline solution. Three new measurements of the patagium thickness at the point of injection were obtained $24 \mathrm{~h}$ later. These three measurements were highly repeatable (pre-injection measurements: $r=0.9, F_{174,350}=36.3$; post-injection measurements: $r=0.9$, $F_{174,350}=43.3$; both $\mathrm{P}<0.0001$ ), so immune response was estimated as change in patagium thickness between average post- and pre-injection measurements, and within-nest means were used in analyses. Wing length was measured with a ruler $( \pm 1 \mathrm{~mm})$ and tarsus length and body mass of all nestlings at 13 days of age were measured, as for adults; brood means were also used in analyses. Fledging success was estimated as number of fledglings (obtained by subtracting any dead nestling found when dismantling nests after fledging from number of nestlings present at nests at their 13 days of age) divided by number of hatchlings.

\subsection{Statistical analyses}

Overall, 59 nests were included in the experiment: 32 aromatic and 27 control nests. Sample sizes differ slightly between analyses because, due to weather or logistic constraints, in one aromatic nest nestling measurements could not be obtained, in one control nest blood-sucking flies could not be quantified at the nestling period, and in another control nest blowfly data were not obtained. In addition, in one aromatic nest the female escaped before weighing, and one control nest failed before nestlings were 12 days old.

The effect of treatment on abundances of nest-dwelling ectoparasites was investigated using a multivariate analysis of variance (MANOVA) with abundances of mites, fleas, and blowflies and its parasitoid as simultaneous dependent variables. The effect of treatment on abundances of blood-sucking flies was investigated using two repeated measures ANOVAs with either abundances of blackflies or biting midges (at incubation and nestling stages) as the repeated measures dependent variable. A MANOVA was also used to test for effects of treatment on nestling measurements and hatching and fledging success, with nestling tarsus length, wing length, body mass, PHA response, hatching success, and fledging success as simultaneous dependent variables. A repeated measures ANOVA was performed with female condition at day 3 and day 13 of nestling age as the repeated measures dependent variable. In all these analyses, treatment (aromatic or control nests), female age (yearlings or adults), and its interaction were included as fixed 
factors. Initial models included clutch size, laying date, and mass of plants added by birds as continuous predictors, and interactions between treatment and mass of plants, and between age and mass of plants. Female age, clutch size, and laying date were included given their potential effects on parasite abundances and breeding performance (Daunt et al., 2001; Møller and de Lope, 1999; Moreno, 1998; Potti and Merino, 1995). Predictors were backward eliminated when not significant (starting with interactions), with the exception of treatment, which was maintained in the models as we were mainly interested in its effect. Non-significant terms were maintained if interactions including any of these terms were significant. In MANOVAs, when a main effect or interaction was significant, univariate F-tests were examined to identify the specific dependent variables that contributed to the significant overall effect.

All analyses were done with Statistica version 6 (Statsoft, Tulsa, Okla.). Abundances of parasites and mass of plants were logarithmically transformed $\left(\log _{10}(x+1)\right.$ and $\log _{10}(x+0.001)$, respectively), and hatching (hatchlings/eggs laid) and fledging success (fledglings/hatchlings) were arcsine square-root transformed, to improve fit to normality. Residuals of the models were tested for normality. Values reported are means $\pm \mathrm{SE}$.

\section{Results}

Age distribution of females in aromatic and control nests did not differ (control: 12/27 adult, aromatic: 14/32 adult; Pearson $x_{1}^{2}=$ $0.0, \mathrm{P}=1.0$ ). Laying date and hatching date did not differ between treatments, but adult females laid eggs earlier and consequently had earlier hatching dates (Table 1). Clutch size, brood size, and mass of plants added by birds to the nest did not differ significantly between treatments and female age classes (Table 1 ).

\subsection{Aromatic plants and parasites}

All nests were infested by two or more parasite species. Mites were found in 50 (86.2\%) nests, fleas in 21 (36.2\%) nests, and blowflies in 53 (93.0\%) nests. Parasitoids of blowflies were found in $45(77.6 \%)$ nests. Blackflies were found in 10 (16.9\%) nests during incubation and in 56 (98.2\%) nests during nestling period, whereas biting midges were found in 22 (37.3\%) nests during incubation and in $57(100 \%)$ nests during nestling period.

Abundance of nest-dwelling ectoparasites showed a nonsignificant tendency to differ between treatments (Table 2), due to control nests having more fleas than aromatic nests (Table 3 ). Interactions between treatment and age, and between treatment and mass of plants, were significant (Table 2). The effect of the interaction between treatment and age was due to a significant interaction effect for abundance of fleas $\left(F_{1,51}=7.8, P<0.01\right.$, Fig. 1$)$. Abundance of fleas in nests of yearling females showed a nonsignificant tendency to be lower in aromatic than in control nests (posthoc test: unequal $\mathrm{N}$ Tukey: $\mathrm{P}=0.12$, Fig. 1 ). The effect of the interaction between treatment and mass of plants was due to a
Table 2

Results of multivariate analysis of variance (MANOVA) to explore effects of experimental supplementation of aromatic plants (treatment) and female age on abundances of nest-dwelling ectoparasites in blue tit nests. ${ }^{a}$

\begin{tabular}{llcc}
\hline & Wilks A & $\mathrm{F}_{4,48}$ & $\mathrm{P}$ \\
\hline Intercept & 0.4 & 17.7 & 0.00 \\
Treatment & 0.8 & 2.2 & 0.08 \\
Female age & 0.9 & 1.6 & 0.2 \\
Mass of plants & 0.9 & 0.8 & 0.5 \\
Treatment $\times$ Female age & 0.8 & 3.8 & 0.01 \\
Treatment $\times$ Mass of plants & 0.8 & 2.6 & $<0.05$ \\
\hline
\end{tabular}

a Only factors that remained in the final model are shown. The whole mode was not significant for abundances of mites, blowflies and its parasitoid, and it was significant for abundance of fleas (adjusted $\mathrm{R}^{2}=0.2, \mathrm{~F}_{5,51}=4.6, \mathrm{P}<0.01$ ).

significant interaction effect for abundance of fleas $\left(\mathrm{F}_{1,51}=10.9\right.$, $\mathrm{P}<0.01$, Fig. 2), so that abundance of fleas was negatively related with mass of plants in control nests, and not in aromatic nests. It also appeared that abundance of fleas was lower in aromatic than in control nests when birds added few plants to their nests (Fig. 2, left side).

Treatment had no effect on abundance of blackflies and biting midges (Tables 3 and 4). Abundance of blackflies during nestling stage was larger in nests of yearling than in nests of adult females (Tables 3 and 4), and increased from incubation to nestling stage, this increment being larger for yearling than for adult females (Table 4 and Fig. 3a). The interaction between time (incubation vs. nestling stage) and clutch size (Table 4) indicated that clutch size was not related to abundance of blackflies during incubation and it was positively related during nestling stage. The interaction between time and mass of plants (Table 4) indicated that mass of plants was not related to abundance of blackflies during incubation

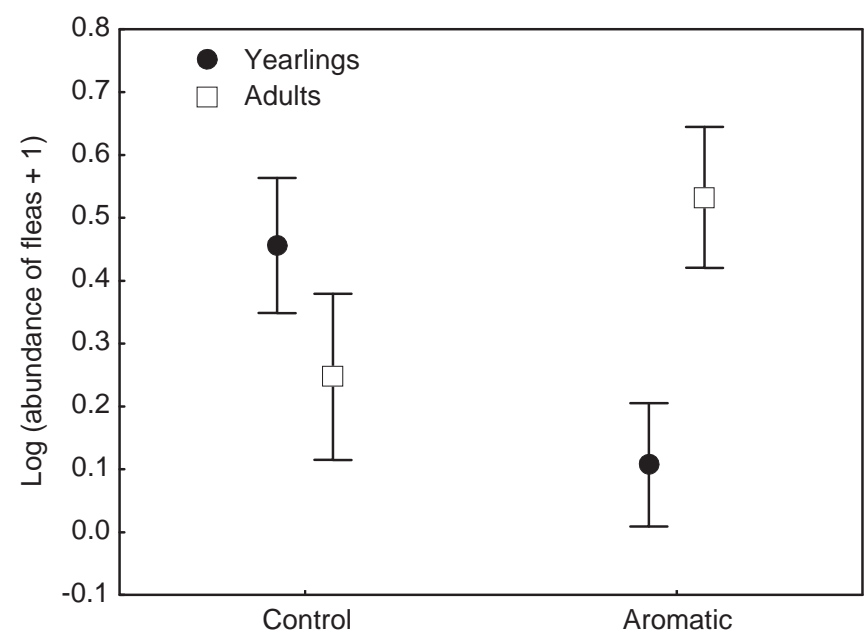

Fig. 1. Interaction between treatment and female age on abundance of fleas in blue tit nests. Least square means $( \pm \mathrm{SE})$ are shown.

Table 1

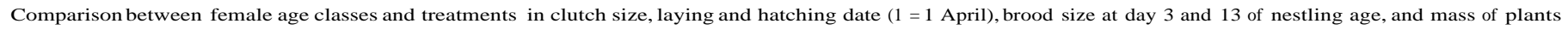
added by females to nests. Mean $\pm \mathrm{SE}$ are shown.

\begin{tabular}{|c|c|c|c|c|c|c|c|c|}
\hline & \multicolumn{4}{|l|}{ Treatment } & \multicolumn{4}{|l|}{ Female age } \\
\hline & Aromatic & Control & $\mathrm{F}$ & $\mathrm{P}$ & Yearling & Adult & F & $\mathrm{P}$ \\
\hline Clutch size & $10.3 \pm 0.2$ & $9.8 \pm 0.3$ & 2.3 & 0.1 & $9.9 \pm 0.3$ & $10.4 \pm 0.2$ & 1.6 & 0.2 \\
\hline Laying date & $29.4 \pm 0.6$ & $29.6 \pm 0.8$ & 0.0 & 0.9 & $30.5 \pm 0.6$ & $28.3 \pm 0.8$ & 5.2 & 0.03 \\
\hline Hatching date & $52.6 \pm 0.5$ & $51.9 \pm 0.6$ & 0.7 & 0.4 & $53.1 \pm 0.5$ & $51.2 \pm 0.6$ & 6.1 & 0.02 \\
\hline Brood size (day 3) & $9.2 \pm 0.3$ & $9.3 \pm 0.4$ & 0.1 & 0.8 & $9.1 \pm 0.4$ & $9.4 \pm 0.4$ & 0.3 & 0.6 \\
\hline Brood size (day 13) & $9.0 \pm 0.4$ & $8.9 \pm 0.5$ & 0.1 & 0.8 & $8.8 \pm 0.4$ & $9.1 \pm 0.4$ & 0.2 & 0.7 \\
\hline Mass of plants (g) & $0.019 \pm 0.004$ & $0.032 \pm 0.010$ & 0.2 & 0.7 & $0.022 \pm 0.004$ & $0.028 \pm 0.011$ & 0.0 & 0.9 \\
\hline
\end{tabular}


Table 3

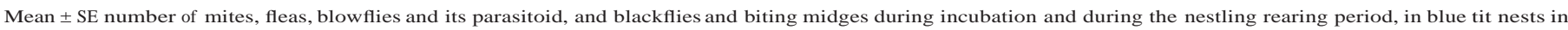
relation to experimental treatment and female age. ${ }^{\text {a }}$

\begin{tabular}{|c|c|c|c|c|c|c|c|c|}
\hline & \multicolumn{4}{|l|}{ Treatment } & \multicolumn{4}{|l|}{ Female age } \\
\hline & Aromatic & Control & $\mathrm{F}$ & $\mathrm{P}$ & Yearling & Adult & $\mathrm{F}$ & $\mathrm{P}$ \\
\hline Mites & $109.7 \pm 29.5$ & $64.1 \pm 28.1$ & 0.2 & 0.6 & $111.6 \pm 31.9$ & $59.8 \pm 22.1$ & 3.4 & 0.1 \\
\hline Fleas & $3.9 \pm 1.9$ & $4.5 \pm 1.6$ & 9.4 & $<0.01$ & $2.5 \pm 0.8$ & $6.4 \pm 2.7$ & 0.9 & 0.3 \\
\hline Blowflies & $26.3 \pm 4.1$ & $26.8 \pm 3.4$ & 0.0 & 1.0 & $27.0 \pm 3.4$ & $25.9 \pm 4.5$ & 0.4 & 0.5 \\
\hline Blowfly parasitoids & $18.3 \pm 6.1$ & $15.1 \pm 3.2$ & 0.5 & 0.5 & $14.9 \pm 4.4$ & $19.4 \pm 6.1$ & 0.8 & 0.4 \\
\hline Blackflies (incubation) & $0.7 \pm 0.3$ & $0.7 \pm 0.2$ & 0.2 & 0.7 & $0.9 \pm 0.3$ & $0.4 \pm 0.2$ & 0.8 & 0.4 \\
\hline Biting midges (incubation) & $0.6 \pm 0.3$ & $0.9 \pm 0.3$ & 1.0 & 0.3 & $0.9 \pm 0.4$ & $0.5 \pm 0.2$ & 1.4 & 0.2 \\
\hline Blackflies (nestling stage) & $13.8 \pm 1.8$ & $9.3 \pm 1.8$ & 1.7 & 0.2 & $14.1 \pm 2.0$ & $8.8 \pm 1.6$ & 7.1 & 0.01 \\
\hline Biting midges (nestling stage) & $152.0 \pm 39.0$ & $81.2 \pm 19.5$ & 0.9 & 0.4 & $166.1 \pm 39.9$ & $63.1 \pm 11.5$ & 7.6 & 0.01 \\
\hline
\end{tabular}

a Univariate tests result from multivariate analysis of variance (MANOVA) and repeated measures ANOVA (see text).

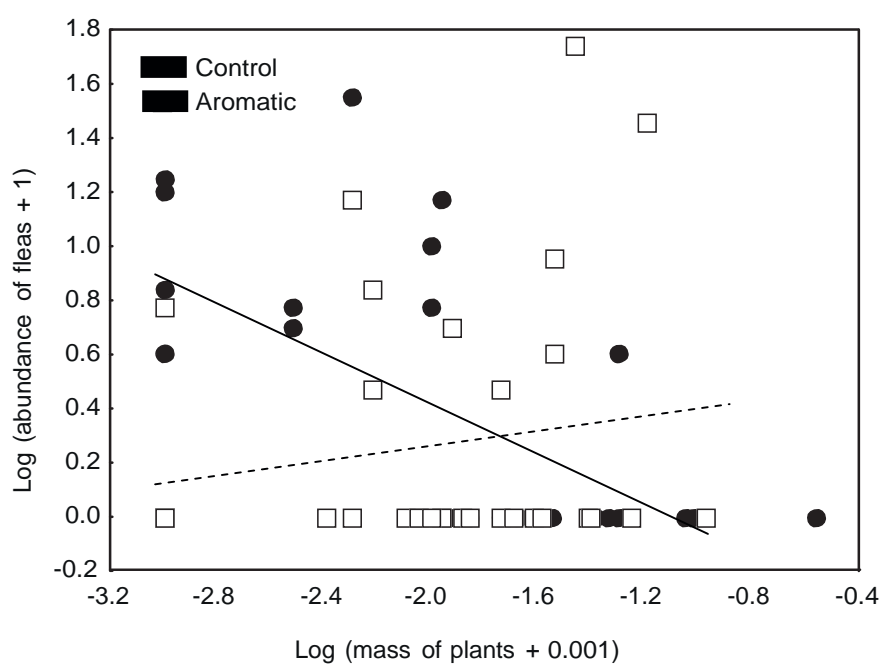

Fig. 2. Effect of interaction between treatment and mass of plants added by birds on abundance of fleas in blue tit nests (control nests: $\mathrm{r}=-0.6, \mathrm{P}<0.01$; aromatic nests: $r=0.2, P=0.4)$.

while it was positively related to abundance of blackflies during nestling stage (Fig. 4).

Abundance of biting midges during nestling stage was positively related to clutch size $\left(F_{1,53}=5.4, P=0.02\right.$, Table 4$)$, was larger in nests of yearling than in nests of adult females (Tables 3 and 4), and increased from incubation to nestling stage, this increment being larger for yearling than for adult females (Table 4 and Fig. 3b).

Table 4

Results of repeated measures ANOVAs to explore effects of experimental supplementation of aromatic plants (treatment) and female age on abundances of blackflies and biting midges in blue tit nests. ${ }^{a}$

\begin{tabular}{|c|c|c|c|c|}
\hline & \multicolumn{2}{|c|}{ Blackflies } & \multicolumn{2}{|c|}{ Biting midges } \\
\hline & $\mathrm{F}_{1,52}$ & $\mathrm{P}$ & $\mathrm{F}_{1,53}$ & $\mathrm{P}$ \\
\hline Intercept & 2.0 & 0.2 & 1.5 & 0.2 \\
\hline Treatment & 1.3 & 0.3 & 0.1 & 0.8 \\
\hline Female age & 5.6 & 0.02 & 7.7 & $<0.01$ \\
\hline Clutch size & 0.6 & 0.5 & 6.3 & 0.02 \\
\hline Mass of plants & 0.7 & 0.4 & & \\
\hline Time & 0.8 & 0.4 & 5.2 & 0.03 \\
\hline Time $\times$ Treatment & 1.1 & 0.3 & 2.1 & 0.2 \\
\hline Time $\times$ Female age & 4.5 & 0.04 & 4.0 & $<0.05$ \\
\hline Time $\times$ Clutch size & 6.4 & 0.02 & 2.2 & 0.2 \\
\hline Time $\times$ Mass of plants & 9.7 & $<0.01$ & & \\
\hline
\end{tabular}

a Only factors that remained in the final models are shown. The whole model was significant for abundance of blackflies during nestling stage (adjusted $R^{2}=0.2$, $\mathrm{F}_{4,52}=4.4, \quad \mathrm{P}<0.01$ ) and for abundance of biting midges during nestling stage (adjusted $\mathrm{R}^{2}=0.2, \mathrm{~F}_{3,53}=4.3, \mathrm{P}<0.01$ )

\subsection{Aromatic plants and effects on nestlings and females}

There was no significant effect of treatment, female age, mass of plants, or its interactions on nestling measurements and hatching and fledging success (MANOVA, Wilks A, all $\mathrm{P}>0.2$; Table 5). Fledging success was negatively related to laying date $\left(\mathrm{F}_{1,54}=12.9\right.$, $\mathrm{P}<0.01$ )

The repeated measures ANOVA on female condition revealed significant effects of age and time, whereas treatment, mass of
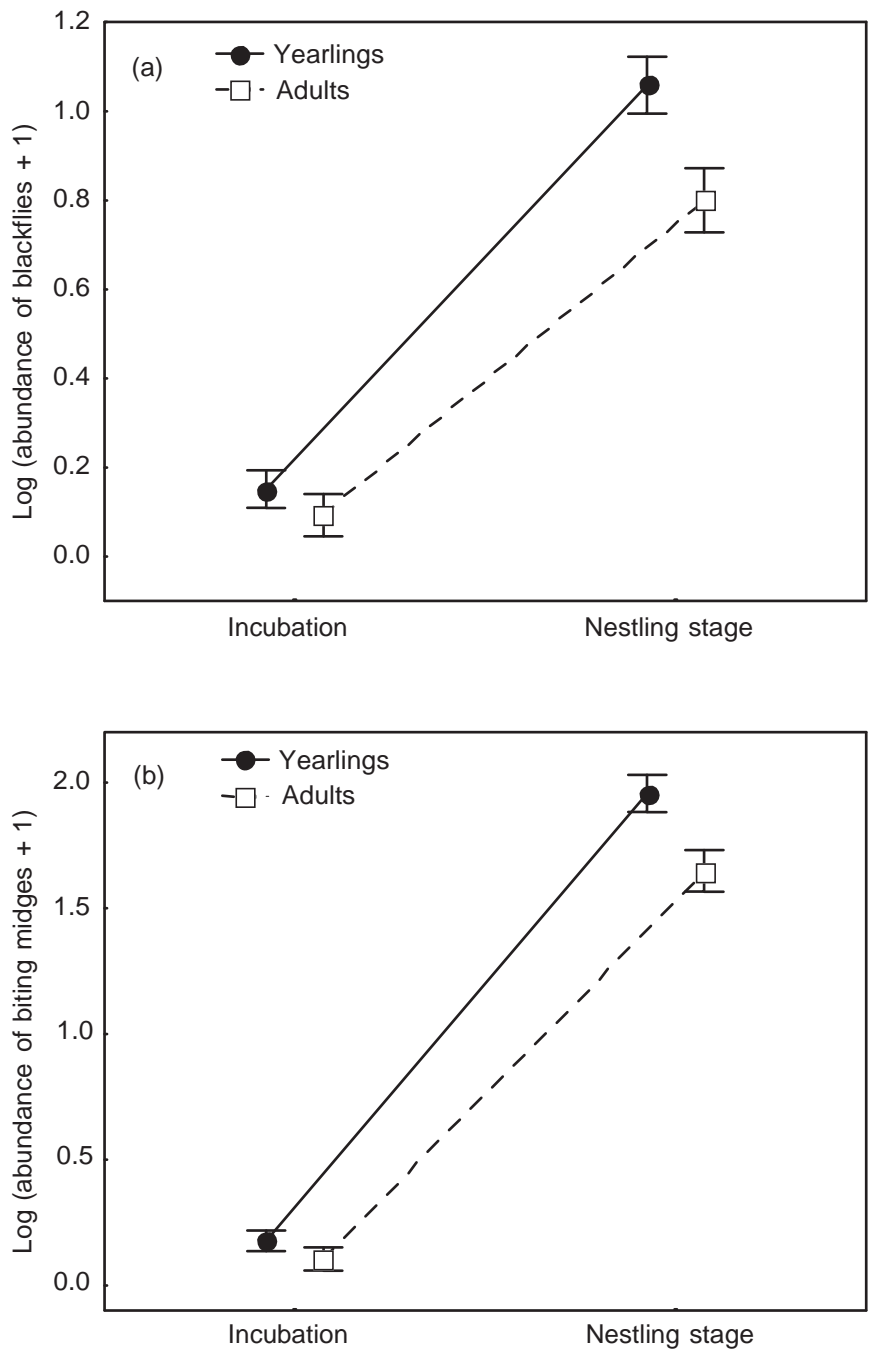

Fig. 3. Effect of female age on abundances of blackflies (a) and biting midges (b) during incubation and during nestling stage in blue tit nests. Least square means $( \pm$ SE) are shown. 
Table 5

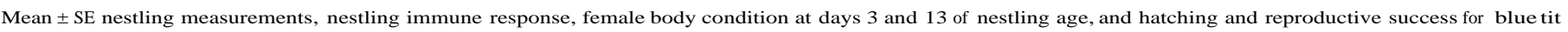
nests in relation to experimental treatment and female age. ${ }^{a}$

\begin{tabular}{|c|c|c|c|c|c|c|c|c|}
\hline & \multicolumn{4}{|l|}{ Treatment } & \multicolumn{4}{|l|}{ Female age } \\
\hline & Aromatic & Control & $\mathrm{F}$ & $\mathrm{P}$ & Yearling & Adult & $\mathrm{F}$ & $\mathrm{P}$ \\
\hline Nestling mass (g) & $10.0 \pm 0.1$ & $9.9 \pm 0.1$ & 0.4 & 0.5 & $9.9 \pm 0.1$ & $10.1 \pm 0.1$ & 1.3 & 0.3 \\
\hline Nestling tarsus length (mm) & $16.2 \pm 0.1$ & $16.1 \pm 0.1$ & 1.7 & 0.2 & $16.1 \pm 0.1$ & $16.2 \pm 0.1$ & 0.5 & 0.5 \\
\hline Nestling wing length (mm) & $40.1 \pm 0.2$ & $39.9 \pm 0.4$ & 0.2 & 0.7 & $39.6 \pm 0.3$ & $40.5 \pm 0.3$ & 4.6 & 0.04 \\
\hline Nestling PHA & $0.35 \pm 0.02$ & $0.38 \pm 0.03$ & 0.7 & 0.4 & $0.35 \pm 0.03$ & $0.39 \pm 0.02$ & 1.3 & 0.3 \\
\hline Female body condition (day 3) (g/mm) & $0.65 \pm 0.01$ & $0.65 \pm 0.01$ & 0.2 & 0.7 & $0.64 \pm 0.00$ & $0.67 \pm 0.01$ & 4.4 & 0.04 \\
\hline Female body condition (day 13) (g/mm) & $0.60 \pm 0.01$ & $0.61 \pm 0.01$ & 0.2 & 0.6 & $0.60 \pm 0.00$ & $0.62 \pm 0.01$ & 3.5 & 0.1 \\
\hline Hatching success ${ }^{\mathrm{b}}$ & $0.90 \pm 0.02$ & $0.92 \pm 0.03$ & 0.7 & 0.4 & $0.92 \pm 0.02$ & $0.90 \pm 0.03$ & 2.4 & 0.1 \\
\hline Fledging success ${ }^{c}$ & $0.96 \pm 0.02$ & $0.95 \pm 0.02$ & 1.0 & 0.3 & $0.95 \pm 0.02$ & $0.97 \pm 0.01$ & 0.1 & 0.8 \\
\hline
\end{tabular}

a Univariate tests result from multivariate analysis of variance (MANOVA) and repeated measures ANOVA (see text).

b Hatching success: hatchlings/eggs laid.

Fledging success: fledglings/hatchlings.

plants, or its interactions were not significant (Wilks $A$, all $\mathrm{P}>0.2$ ). Female condition decreased from day 3 to day 13 of nestling age $\left(\mathrm{F}_{1,53}=6.5, \mathrm{P}=0.01\right)$, while adult females had a better condition than yearling females at day 3 of nestling age (Table 5).

\section{Discussion}

We found a significant interaction between treatment and female age on abundance of fleas. In nests of yearling females, aromatic plants tended to reduce flea abundances, whereas this was not the case in nests of adult females. Dawson (2004) found that aromatic tree swallow nests had larger abundances of fleas than control nests. He also found that, considering only yearling females, hatching success was higher in aromatic than in control nests, a result that he attributed to unobserved parasites to which yearling females may be particularly susceptible. Our results suggest that treatment may be more beneficial in nests of yearling, inexperienced females, whereas it may be less beneficial in nests of adult females which may rely on other defences against ectoparasitism such as nest sanitation behaviours (Hurtrez-Boussès et al., 2000). This differential effect of treatment between female ages may underlie the contradictory results found in the literature regarding effects of aromatic plants on abundance of fleas (Dawson, 2004; Shutler and Campbell, 2007).

In line with this, we also found that female age was an important determinant of both blackfly and biting midge abundances, as shown by the significant interactions between time and female age

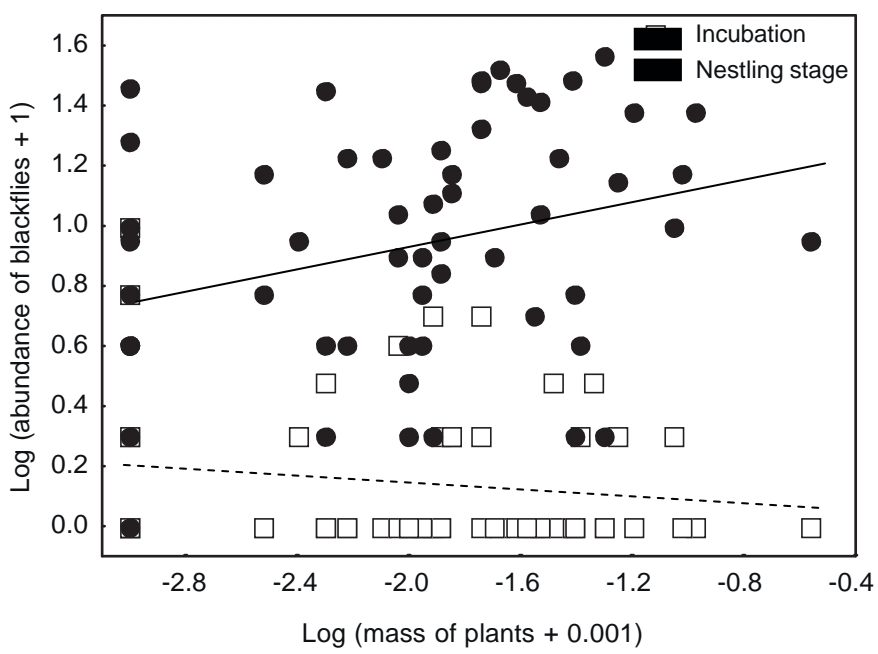

Fig. 4. Effect of mass of plants added by blue tits to their nests on abundance of blackflies during incubation and during nestling stage (incubation: $\mathrm{r}=-0.2, \mathrm{P}=0.2$; nestling stage: $\mathrm{r}=0.3, \mathrm{P}=0.03$ ). on these parasites. Blackfly and biting midge abundances did not differ between female age classes during incubation, but both were significantly higher in yearling females than in adult females during nestling stage. Age has an important effect on overall reproductive performance, because in general, older individuals reproduce earlier in the season (Moreno, 1998; Perdeck and Cavé, 1992) and are of higher phenotypic quality, either by means of improvement through previous breeding experience or by means of selective disappearance of lower quality individuals (Verhulst and Nilsson, 2008). Thus, female age may have had an effect on insect abundances due to differences in phenotypic quality, or to the observed delayed breeding of yearling females and the associated seasonal decline in reproductive performance. This latter possibility would not be supported by our results, since laying date was never retained in the models on parasites. Age of birds can be associated with intensity of ectoparasitism (Daunt et al., 2001; Møller and de Lope, 1999; Potti and Merino, 1995). Our results indicate that age mediates the relationship between aromatic plants and abundance of fleas, and show that nests of adult birds are less parasitized by blood-sucking flies than nests of yearling birds. This latter result is noteworthy given the scant knowledge we still have on ecological interactions between these parasites and their hosts (Martínez-de la Puente et al., 2009b; Tomás et al., 2008a).

Interestingly, we found that mass of plants added to nests by blue tits interfered in the detected relationships, because in control nests, a larger amount of plants added by birds was associated with lower abundances of fleas, whereas this pattern did not appear in aromatic nests. In addition, abundance of fleas was lower in aromatic than in control nests only when birds added few plants to the nest. Thus, experimental supplementation of aromatic plants allowed birds to maintain low abundances of fleas, irrespective of the amount of plants they added to the nest, while under natural conditions (i.e. control nests) only females that added large amounts of plants had low abundances of fleas. Mass of plants added by birds was apparently not affected by treatment or female age, but plants may be differentially added by birds depending on several factors, including parasite species involved. It should be noted that flea abundances were low in the study year as compared to a previous year (Tomás et al., 2007). On the other hand, we found no effect of aromatic plants on abundance of mites and blowflies, in accordance with most studies to date (Brouwer and Komdeur, 2004; Gwinner et al., 2000; Mennerat et al., 2008; Shutler and Campbell, 2007). We also found no effect of aromatic plants on abundance of a wasp parasitoid of blowflies, and thus the prediction that addition of aromatic plants may be a strategy of birds to attract parasitoids of nest ectoparasites (see also Dawson, 2004) is not supported by our results.

We found no effect of treatment or any of its interactions on abundances of blackflies and biting midges, for both incubation and nestling stage. This result does not support the hypothesized 
role of aromatic plants in protecting incubating females (Banbura et al., 1995; Cowie and Hinsley, 1988; Lambrechts and Dos Santos, 2000), or nestlings (Dawson, 2004; Lafuma et al., 2001; Mennerat et al., 2008; Wimberger, 1984), from blood-sucking flies. It should be noted, however, that prevalence and abundance of these insects in nests during incubation were considerably low, and hence this result may be interpreted with caution. However, mass of plants added by birds to their nests was related to blackfly abundance, this relationship varying from incubation to nestling stage. While mass of plants was not related to abundance of blackflies during incubation, it was positively related to abundance of blackflies during nestling stage. This suggests that birds may use aromatic plants with a therapeutic role, adding more plants to their nests when parasite abundances are higher (Clark, 1991; Lozano, 1998).

Our results do not seem to support the drug hypothesis, as we found no effects of experimental supplementation of plants or of mass of plants added by birds on nestling measurements (including PHA response) or fledging success. We have measured only one aspect of immunity commonly estimated in ecological studies, so we cannot completely rule out that other branches of the immune system may be affected by treatment (Gwinner et al., 2000; Mennerat et al., 2009a).

To sum up, our results indicate that female age has an important effect on abundance of blood-sucking flies and may mediate the effect of aromatic plants on nest-dwelling ectoparasites. Also, our study shows that mass of aromatic plants added by birds interacted with the manipulation, given the observed positive association between mass of plants and blackfly abundance during nestling stage, and the negative association between mass of plants and flea abundance in control nests that did not show up in aromatic nests. Thus, several factors such as female experience and their ability to add plants to the nest (together with variation in plant preferences and availability among areas; Mennerat et al., 2009b) need to be considered to properly understand the complex interactions governing effects of aromatic plants on different parasites in birds' nests.

\section{Acknowledgments}

We thank S. Ippi and Ó. Gordo for their help during fieldwork and J. Donés (Director of 'Montes de Valsaín') for permission to work in the study area. This study was funded by projects BOS2003-05724 and CGL2009-09439 from Ministerio de Ciencia e Innovación (to S.M.) and CGL2007-61251 (to J. Moreno). J.M.-P. is supported by a JAE postdoctoral contract from CSIC, J. Morales by programme Juan de la Cierva, and E.L. by a postdoctoral contract from MICINN. S.d.C. is supported by a grant from Comunidad de Madrid. G.T. was supported by an I3P postdoctoral contract from CSIC during fieldwork and by programme Juan de la Cierva during final analyses and writing. This study is a contribution to research developed at El Ventorrillo field station. A. Pilastro and five anonymous reviewers made useful comments on a previous draft.

\section{References}

Banbura, J., Blondel, J., de Wilde-Lambrechts, H., Perret, P., 1995. Why do female blue tits (Parus caeruleus) bring fresh plants to their nests? Journal für Ornithologie 136, 217-221.

Bennett, G.F., Whitworth, T.L., 1991. Studies on the life-history of some species of Protocalliphora (Diptera, Calliphoridae). Canadian Journal of Zoology 69, 2048-2058.

Bennett, G.F., Whitworth, T.L., 1992. Host, nest, and ecological relationships of species of Protocalliphora (Diptera, Calliphoridae). Canadian Journal of Zoology 70, 51-61.

Brouwer, L., Komdeur, J., 2004. Green nesting material has a function in mate attraction in the European starling. Animal Behaviour 67, 539-548.

Bucher, E.H., 1988. Do birds use biological control against nest parasites? Parasitology Today 4, 1-3.
Clark, L., 1991. The nest protection hypothesis: the adaptive use of plant secondary compounds by European starlings. In: Loye, J.E., Zuk, M. (Eds.), Bird-Parasite Interactions: Ecology, Evolution and Behaviour. Oxford University Press, Oxford, pp. 205-221.

Clark, L., Mason, J.R., 1985. Use of nest material as insecticidal and anti-pathogenic agents by the European starling. Oecologia 67, 169-176.

Clark, L., Mason, J.R., 1988. Effect of biologically active plants used as nest material and the derived benefit to starling nestlings. Oecologia 77, 174-180.

Cowie, R.J., Hinsley, S.A., 1988. Timing of return with green vegetation by nesting Blue Tits Parus caeruleus. Ibis 130, 553-555.

Cramp, S., Perrins, C.M., 1998. The Complete Birds of the Western Palearctic on CDROM, Version 1.0 for PC. Oxford University Press, Oxford.

Daunt, F., Monaghan, P., Wanless, S., Harris, M.P., 2001. Parental age and offspring ectoparasite load in European Shags Stictocarbo aristotelis. Ardea 89, 449-455.

Dawson, R.D., 2004. Does fresh vegetation protect avian nests from ectoparasites? An experiment with tree swallows. Canadian Journal of Zoology 82, 1005-1010.

Fargallo, J.A., 2004. Latitudinal trends of reproductive traits in the blue tit Parus caeruleus. Ardeola 51, 177-190.

Fargallo, J.A., Johnston, R.D., 1997. Breeding biology of the blue tit Parus caeruleus in a montane Mediterranean deciduous forest: the interaction of latitude and altitude. Journal für Ornithologie 138, 83-92.

Fauth, P.T., Krementz, D.G., Hines, J.E., 1991. Ectoparasitism and the role of green nesting material in the European starling. Oecologia 88, 22-29.

Gwinner, H., 1997. The function of green plants in nests of European starlings (Sturnus vulgaris). Behaviour 134, 337-351.

Gwinner, H., Berger, S., 2005. European starlings: nestling condition, parasites and green nest material during the breeding season. Journal of Ornithology 146, 365-371.

Gwinner, H., Oltrogge, M., Trost, L., Nienaber, U., 2000. Green plants in starling nests: effects on nestlings. Animal Behaviour 59, 301-309.

Hurtrez-Boussès, S., Renaud, F., Blondel, J., Perret, P., Galán, M.J., 2000. Effects of ectoparasites of young on parents' behaviour in a Mediterranean population of Blue Tits. Journal of Avian Biology 31, 266-269.

Lafuma, L., Lambrechts, M.M., Raymond, M., 2001. Aromatic plants in bird nests as a protection against blood-sucking flying insects? Behavioural Processes 56, $113-120$.

Lambrechts, M.M., Dos Santos, A., 2000. Aromatic herbs in Corsican blue tit nests: The 'Potpourri' hypothesis. Acta Oecologica 21, 175-178.

Lozano, G.A., 1998. Parasitic stress and self-medication in wild animals. In: Møller, A.P., Milinski, M., Slater, P.J.B. (Eds.), Advances in the Study of Behavior, vol. 27, Stress and Behaviour. Academic Press, London, pp. 291-317.

Malmqvist, B., Strasevicius, D., Hellgren, O., Adler, P.H., Bensch, S., 2004. Vertebrate host specificity of wild-caught blackflies revealed by mitochondrial DNA in blood. Proceedings of the Royal Society of London, Series B 271 (Suppl.), S152-S155.

Martin, L.B., Han, P., Lewittes, J., Kuhlman, J.R., Klasing, K.C., Wikelski, M., 2006. Phytohemagglutinin-induced skin swelling in birds: histological support for a classic immunoecological technique. Functional Ecology 20, 290-299.

Martínez-de la Puente, J., Merino, S., Lobato, E., Rivero-de Aguilar, J., del Cerro, S., Ruiz-de-Castañeda, R., Moreno, J., 2009a. Does weather affect biting fly abundance in avian nests? Journal of Avian Biology 40, 653-657.

Martínez-de la Puente, J., Merino, S., Tomás, G., Moreno, J., Morales, J., Lobato, E., Talavera, S., Sarto i Monteys, V., 2009b. Factors affecting Culicoides species composition and abundance in avian nests. Parasitology 136, 1033-1041.

Martínez-de la Puente, J., Merino, S., Lobato, E., Rivero-de Aguilar, J., del Cerro, S., Ruiz-de-Castañeda, R., Moreno, J., 2010. Nest-climatic factors affect the abundance of biting flies and their effects on nestling condition. Acta Oecologica 36, 543-547.

Mellor, P.S., Boorman, J., Baylis, M., 2000. Culicoides biting midges: their role as arbovirus vectors. Annual Review of Entomology 45, 307-340.

Mennerat, A., Perret, P., Caro, S.P., Heeb, P., Lambrechts, M.M., 2008. Aromatic plants in blue tit Cyanistes caeruleus nests: no negative effect on blood-sucking Protocalliphora blow fly larvae. Journal of Avian Biology 39, 127-132.

Mennerat, A., Perret, P., Bourgault, P., Blondel, J., Gimenez, O., Thomas, D.W., Heeb, P., Lambrechts, M.M., 2009a. Aromatic plants in nests of blue tits: positive effects on nestlings. Animal Behaviour 77, 569-574.

Mennerat, A., Perret, P., Lambrechts, M.M., 2009b. Local individual preferences for nest materials in a passerine bird. Plos One 4, e5104.

Mennerat, A., Mirleau, P., Blondel, J., Perret, P., Lambrechts, M.M., Heeb, P., 2009c. Aromatic plants in nests of the blue tit Cyanistes caeruleus protect chicks from bacteria. Oecologia 161, 849-855.

Merino, S., Potti, J., 1995. Mites and blowflies decrease growth and survival in nestling pied flycatchers. Oikos 73, 95-103.

Merino, S., Martínez, J., Møller, A.P., Sanabria, L., de Lope, F., Pérez, J., RodríguezCaabeiro, F., 1999. Phytohaemagglutinin injection assay and physiological stress in nestling house martins. Animal Behaviour 58, 219-222.

Merino, S., Moreno, J., Tomás, G., Martínez, J., Morales, J., Martínez-de la Puente, J., Osorno, J.L., 2006. Effects of parental effort on blood stress protein HSP60 and immunoglobulins in female blue tits: a brood size manipulation experiment. Journal of Animal Ecology 75, 1147-1153.

Møller, A.P., de Lope, F., 1999. Senescence in a short-lived migratory bird: agedependent morphology, migration, reproduction and parasitism. Journal of Animal Ecology 68, 163-171.

Moreno, J., 1998. The determination of seasonal declines in breeding success in seabirds. Etología 6, 17-31. 
Moreno, J., Merino, S., Lobato, E., Ruiz-de Castañeda, R., Martínez-de la Puente, J., del Cerro, S., Rivero-de Aguilar, J., 2009. Nest-dwelling ectoparasites of two sympatric hole-nesting passerines in relation to nest composition: an experimental study. Ecoscience 16, 418-427.

Ontiveros, D., Caro, J., Pleguezuelos, J.M., 2008. Green plant material versus ectoparasites in nests of Bonelli's Eagle. Journal of Zoology 274, 99-104.

Perdeck, A.C., Cavé, A.J., 1992. Laying date in the coot: effects of age and mate choice. Journal of Animal Ecology 61, 13-19.

Petit, C., Hossaert-McKey, M., Perret, P., Blondel, J., Lambrechts, M.M., 2002. Blue tits use selected plants and olfaction to maintain an aromatic environment for nestlings. Ecology Letters 5, 585-589.

Polo, V., Veiga, J.P., Cordero, P.J., Viñuela, J., Monaghan, P., 2004. Female starlings adjust primary sex ratio in response to aromatic plants in the nest. Proceedings of the Royal Society of London, Series B 271, 1929-1933.

Potti, J., Merino, S., 1995. Louse loads of pied flycatchers-effects of hosts sex, age, condition and relatedness. Journal of Avian Biology 26, 203-208.

Proctor, H., Owens, I., 2000. Mites and birds: diversity, parasitism and coevolution. Trends in Ecology and Evolution 15, 358-364.

Rheinwald, G., 1972. Blaumeise (Parus caeruleus) dekoriert ihr Nest mit Blättern von Brennesseln (Urtica dioica). Ornithologische Mitteilungen 24, 47.

Shutler, D., Campbell, A.A., 2007. Experimental addition of greenery reduces flea loads in nests of a non-greenery using species, the tree swallow Tachycineta bicolor. Journal of Avian Biology 38, 7-12.

Smits, J.E., Bortolotti, G.R., Tella, J.L., 1999. Simplifying the phytoheamagglutinin skin-testing technique in studies of avian immunocompetence. Functional Ecology $13,567-572$.
Svensson, L., 1992. Identification Guide to European Passerines, Lars Svensson, Stockholm.

Taverner, P.A., 1933. Purple martins gathering leaves. Auk 50, 110-111.

Tomás, G., Merino, S., Moreno, J., Morales, J., 2007. Consequences of nest reuse for parasite burden and female health and condition in blue tits, Cyanistes caeruleus. Animal Behaviour 73, 805-814.

Tomás, G., Merino, S., Martínez-de la Puente, J., Moreno, J., Morales, J., Lobato, E., 2008a. A simple trapping method to estimate abundances of blood-sucking flying insects in avian nests. Animal Behaviour 75, 723-729.

Tomás, G., Merino, S., Martínez-de la Puente, J., Moreno, J., Morales, J., Lobato, E., 2008b. Determinants of abundance and effects of blood-sucking flying insects in the nest of a hole-nesting bird. Oecologia 156, 305-312.

Veiga, J.P., Polo, V., Viñuela, J., 2006. Nest green plants as a male status signal and courtship display in the spotless starling. Ethology 112, 196-204.

Verhulst, S., Nilsson, J.A., 2008. The timing of birds' breeding seasons: a review of experiments that manipulated timing of breeding. Philosophical Transactions of the Royal Society of London, Series B 363, 399-410.

Votýpka, J., Synek, P., Svobodová, M., 2009. Endophagy of biting midges attacking cavity-nesting birds. Medical and Veterinary Entomology 23, 277-280.

Whiting, A.R., 1967. The biology of the parasitic wasp Mormoniellavitripennis [=Nasonia brevicornis] (Walker). The Quarterly Review of Biology 42, 333406.

Wimberger, P.H., 1984. The use of green material in bird nests to avoid ectoparasites. Auk 101, 615-618. 